\title{
Effect of spectral overlays on visual parameters and reading ability: an integrative review
}

\author{
Douglas de Araújo Vilhena ${ }^{1,2,3}$ \\ https://orcid.org/0000-0003-2670-7963 \\ Márcia Reis Guimarães ${ }^{1}$ \\ https://orcid.org/0000-0002-5475-5375 \\ Ricardo Queiroz Guimarães ${ }^{1}$ \\ https://orcid.org/0000-0001-7600-855X \\ Ângela Maria Vieira Pinheiro, \\ https://orcid.org/0000-0002-5852-4320
}

\begin{abstract}
Hospital de Olhos de Minas Gerais Dr. Ricardo Guimarães, Laboratório de Pesquisa Aplicada à Neurociências da Visão - LAPAN, Belo Horizonte, Minas Gerais, Brasil.

2 Universidade Federal de Minas Gerais, Programa de Pós-Graduação em Psicologia: Cognição e Comportamento, Laboratório de Processos Cognitivos LabCog, Belo Horizonte, Minas Gerais, Brasil.

${ }^{3}$ Universidade do Porto, Faculdade de Psicologia e de Ciências da Educação, Porto, Douro Litoral, Portugal.
\end{abstract}

Research support source: This study was financed in part by the Coordenação de Aperfeiçoamento de Pessoal de Nível Superior - Brasil (CAPES) - Finance Code 001.

Conflict of interests: Nonexistent

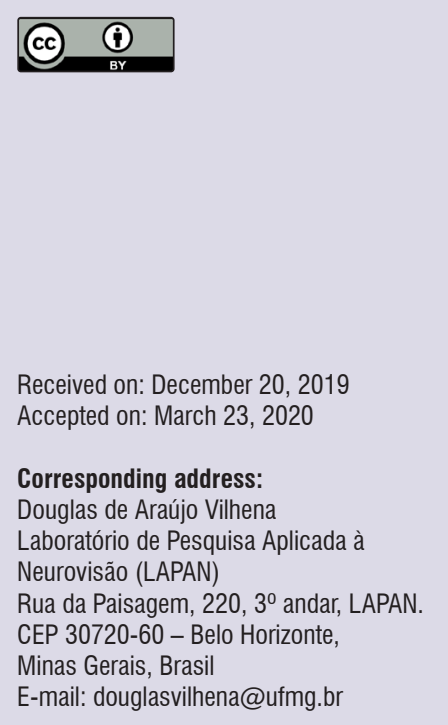

\section{ABSTRACT}

Purpose: to provide an integrative review of indexed articles published from 2009 to 2019 on the effect of spectral overlays on visual parameters and reading ability.

Methods: keywords were used to search seven databases. Duplicate entries, reviews, literature reviews, editor's comments, and congress abstracts were excluded, as well as papers that were not relevant, based on their titles and abstracts. A total of 52 articles, which were read in full, were eligible at this stage. Of these, 12 articles, published in Portuguese or English from 2009 to 2019, were included.

Results: all 12 articles included evaluated the effect of overlays on the reading rate. There was an improvement in different visual parameters (ocular accommodation and eye movement), facial recognition, and reading (reading rate, relative efficiency, and comprehension). The use of overlays reduced visual stress regardless of refractive, orthoptic or cognitive disorders. The associated conditions investigated were autism spectrum disorder, Tourette syndrome, stroke, deafness, dyslexia, and auditory temporal processing disorder.

Conclusion: the effectiveness of overlays in improving reading quality is consistently demonstrated in the literature. The reviewed articles showed that the overlays' effect is more expressive when the visual stress is associated with conditions that present sensory alterations and cortical hyperactivity.

Keywords: Reading; Visual Perception; Learning Disorders; Vision Disorders 


\section{INTRODUCTION}

Visual stress is a perceptual disorder that causes visual perceptual distortion symptoms, which are manifested when the person reads texts and are expressed as visual discomfort, rapid fatigue, photosensitivity, irritability under fluorescent light, and deficit in depth perception ${ }^{1-3}$. The most reported distortions are halos around the words, irregular spacing in-between line of the text, and an impression of movement as letters vibrating or detaching from the paper ${ }^{4}$. The efforts to compensate these difficulties lead to complaints of progressive visual fatigue, eye pain, teary eyes, excessive blinking, headache or migraine ${ }^{5,6}$. The above mentioned visual manifestations cause reading difficulties and require an attentive interdisciplinary evaluation to reach a diagnosis differentiated from that of nonvisual reading disorders ${ }^{1,7-9}$.

Spectral overlays (colored transparent sheets placed over the text) have been used to reduce visual stress, to minimize distortions and visual discomfort when reading. This material is made of acetate and its resistance makes it fit for daily use in the classroom. Overlays are manufactured in a wide selection of spectral-filtering colors, one side matte and the other shiny. Since no color generally improves reading performance for all, it is necessary to individually present the overlay options and its superimposing combinations, which is a specific and consistent idiosyncratic selection process ${ }^{2}$.

The systematic review by Evans and Allen ${ }^{7}$, which encompassed ten studies using spectral overlays, shows that such an intervention, besides being safe and noninvasive, relieves the asthenopia symptoms and improves the reading performance of the patients with visual stress. Visual stress clinical investigation conducted by a health or education professional can reduce the likelihood of a false positive due to choosing the treatment for nonclinical reasons, such as aesthetical preference, placebo effect (since it is not possible to completely mask the overlays from the participants) or attributional (excuses under-achieving). The spectral overlays are also used to identify visual stress; an improvement of at least $\geq 15 \%$ in reading rate when using overlays and its voluntary use for at least three months are diagnostical signs ${ }^{10}$.

The rate of reading test (RRT) is recurrently used in the literature to assess the effect of the overlays. It was developed based on the theory that visual stress is caused by cortical hyperexcitability due to the pattern of horizontal lines and intense visual activity ${ }^{11}$. The words psycholinguistic characteristics (high frequency, simple structure, short 2 to 4 letter words) make reading easier even for participants who are beginning their process of learning how to read. The visual structure of the RRT, with its 9-point font size and single spacing, intensifies visual stress.

The RRT assesses the efficiency of the visual, cognitive and phono-articulatory processes involved in lexical recognition and in pronouncing, aloud, 15 words known to the reader. The words are randomly repeated in 20 lines, within a limited time, and its score is given in words read per minute (reading rate). To quantify the effect of the spectral overlays on the reading rate, the procedure in applying the instrument includes reading aloud five different lists of stimuli - one for training and four for testing. In the training and tests 2 and 3 , the words are read normally; whereas, in tests 1 and 4, they are read with the spectral overlay that best suits the reader for comfort (ABBA application sequence). The instrument has given evidence of reliability and validity for different languages, including Portuguese ${ }^{12}$.

As demonstrated in another systematic review of the literature ${ }^{13}$, the effect of the overlays on the reading rate is presented in a progressive line of intensity, with mild $(5 \%)$, moderate (10 to $15 \%)$ or substantial gain $(25 \%)$. The gain criterion of at least $\geq 5 \%$ in reading rate with the overlays is the most used in population research and screening ${ }^{13}$. The criterion of $\geq 15 \%$, in its turn, has clinical significance, as it is a diagnostical sign of visual stress and represents an increase beyond the intraindividual variation interval ${ }^{10,14}$. Vilhena, Guimarães and Guimarães ${ }^{13}$ argue that the most rigorous reading rate gain criterion $(\geq 25 \%)$ may not reflect the actual proportion of the population with substantial reading improvement with overlays, especially among adults. This is due to the ceiling effect in the RRT, which has a phono-articulatory time limit for reading aloud. In order not to mistake for other percentages reported in this study, the greater than or equal to sign $(\geq)$ precedes the RRT cutoff criteria values.

The accumulation of scientific articles on the efficiency of the overlays has endorsed their growing daily use in the classroom. This study aims to offer an integrative review of the indexed articles published throughout the last decade on the effect of the spectral overlays on visual parameters and reading abilities. With this synthesis, it is expected that the literature on the therapeutic effects of the overlays become known and accessible to Brazilian schools and health professionals. 


\section{METHODS}

This research is an integrative literature review. To guide the review, the following research question was developed: "What are the results in the indexed scientific articles regarding intervention with spectral overlays?". The electronic databases researched were ERIC (Education Resources Information Center), PubMed (Digital Biomedical Archives and Health Sciences of the US National Institutes of Health), ScienceDirect, SciVerse Scopus, PePSIC (Psychology Electronic Journals), and SciELO (Scientific Electronic Library Online). The articles researched were the full-text ones, published in Portuguese and English from 2009 to 2019, whose title, abstract or keywords had the following terms: spectral/colored overlays, Irlen, Meares-Irlen, scotopic sensitivity syndrome, and visual stress. The terms 'visual discomfort', 'asthenopia' and 'visual fatigue' were not used, as they do not require the use of overlays as a means of intervention.

The flowchart with the article analysis and selection process is presented in Figure 1, following the checklist recommendation in the Preferred Reporting Items for Systematic Reviews and Meta-Analyses (PRISMA). Altogether, 225 papers were found in the databases. Duplicate entries $(n=-68)$ were excluded, as well as reviews, literature reviews, editor's comments, and event abstracts $(n=-45)$. The title and abstract of the remaining articles $(n=120)$ were independently evaluated by two researchers; those that did not present results of the use of overlays $(n=-68)$ were excluded. Hence, in this stage of eligibility, 52 articles on the use of overlays were found, which were all fully read. In the final stage, 12 articles were selected to comprise this integrative review.

The articles were organized in chronological order of publication, along with the summary of results focusing on the effects of the overlays (Table 1). Concerning language, all articles $(n=12)$ had been published in English, with one with a version in Portuguese as well ${ }^{15}$. As for the country of origin, the study reported in these articles were mainly conducted in England $(n=8)$, followed by Brazil $(n=3)$ and Scotland $(n=$ 1). Regarding conditions, all the reviewed articles had studied visual stress; two of them had autism spectrum disorder associated, whereas each of the following conditions was present in one article: Tourette syndrome, stroke, deafness, dyslexia, and auditory temporal processing disorder. As for the conclusions of the articles, $10(83 \%)$ were favorable to the use of overlays, $1(8 \%)$ was partially favorable, and $1(8 \%)$ was unfavorable. The reading rate was evaluated in all the 12 articles reviewed.
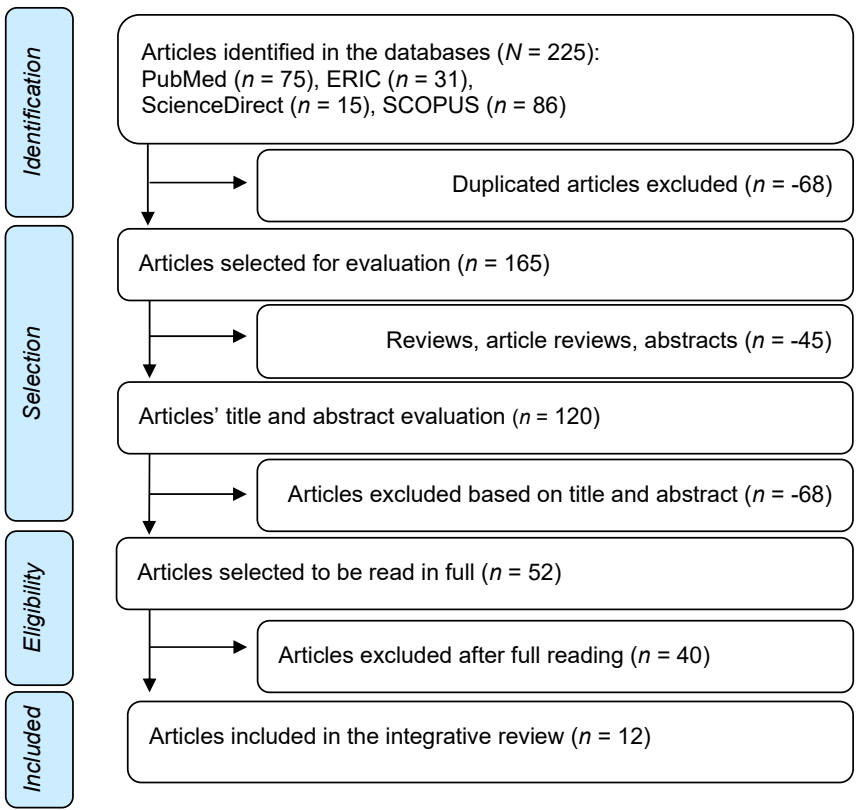

Figure 1. Flowchart of the studies' identification and selection process, following the recommendation by the Preferred Reporting Items for Systematic Reviews and Meta-Analyses (PRISMA) 
Table 1. Characterization of the twelve articles included in the review, regarding intervention with overlays, in chronological order, according to authors, year of publication, title, city, country, number of participants ( $\mathrm{N}=$ clinical condition + control), favorable/partially favorable/unfavorable to the use of overlays, and summary of the results

\begin{tabular}{|c|c|c|c|}
\hline Authors (year) & Original title of the article & $\begin{array}{l}\text { City, country, N, } \\
\text { clinical conditions }\end{array}$ & Summary of the results \\
\hline $\begin{array}{l}\text { Allen, Hussain, } \\
\text { Usherwood, and } \\
\text { Wilkins (2010) }\end{array}$ & $\begin{array}{l}\text { Pattern-related visual } \\
\text { stress, chromaticity, and } \\
\text { accommodation }\end{array}$ & $\begin{array}{l}\text { Cambridge, England } \\
\mathrm{N}=11+11 \\
\text { Visual stress }\end{array}$ & $\begin{array}{l}\text { Favorable. Adults with visual stress, using spectral overlays, improved their reading } \\
\text { rate by } 9.9 \% \text { and reduced the accommodation delay, which did not happen with the } \\
\text { asymptomatic control group. }\end{array}$ \\
\hline $\begin{array}{l}\text { Ritchie, Della Sala, } \\
\text { and McIntosh } \\
\quad(2011)\end{array}$ & $\begin{array}{l}\text { Irlen colored overlays do not } \\
\text { alleviate reading difficulties }\end{array}$ & $\begin{array}{l}\text { Port Glasgow, Scotland } \\
\qquad \begin{array}{l}\mathrm{N}=47+14 \\
\text { Visual stress }\end{array}\end{array}$ & $\begin{array}{l}\text { Unfavorable. There was no difference in reading performance regarding the type of } \\
\text { overlay (ideal, not-ideal, transparent) nor between the screened group with visual } \\
\text { stress and children in the control group. } 32 \% \text { of the sample had gains greater than } \\
\geq 5 \% \text { in the reading rate. }\end{array}$ \\
\hline $\begin{array}{l}\text { Allen, Dedi, Kumar, } \\
\text { Patel, Aloo, and } \\
\text { Wilkins (2012) }\end{array}$ & $\begin{array}{l}\text { Accommodation, pattern } \\
\text { glare, and coloured overlays }\end{array}$ & $\begin{array}{l}\text { Cambridge, England } \\
\qquad \begin{array}{l}\mathrm{N}=18+18 \\
\text { Visual stress }\end{array}\end{array}$ & $\begin{array}{l}\text { Favorable. Adults with visual stress, when using spectral overlays, improved their } \\
\text { reading rate by } 10.4 \% \pm 4.8 \% \text { and reduced by } 45 \% \text { the ocular accommodation } \\
\text { delay (from } 0.95 \mathrm{D} \text { to } 0.52 \mathrm{D}, \mathrm{p}=0.0001 \text { ), leveling their results with those from } \\
\text { the control group. }\end{array}$ \\
\hline $\begin{array}{l}\text { Ludlow, Taylor- } \\
\text { Whiffen, and Wilkins } \\
\text { (2012) }\end{array}$ & $\begin{array}{l}\text { Coloured filters enhance the } \\
\text { visual perception of social } \\
\text { cues in children with autism } \\
\text { spectrum disorders }\end{array}$ & $\begin{array}{l}\text { Birmingham, England } \\
\qquad \mathrm{N}=15+15 \\
\text { Visual stress and Autism } \\
\text { Spectrum Disorder }\end{array}$ & $\begin{array}{l}\text { Favorable. More words per minute were read with overlays than without them }(p< \\
0.001) \text {. More participants in the group with autism spectrum disorder }(80 \%) \text {, when } \\
\text { using overlays, obtained gains of at least } \geq 5 \% \text { in reading rate, when compared } \\
\text { with the control group (33\%). When using overlays, the autistic children improved } \\
\text { in } 18 \% \text { the recognition of facial expressions of emotion, with no significant } \\
\text { improvement in the control group. }\end{array}$ \\
\hline $\begin{array}{l}\text { Beasley and Davies } \\
\text { (2013) }\end{array}$ & $\begin{array}{l}\text { Visual stress symptoms } \\
\text { secondary to stroke alleviated } \\
\text { with spectral filters and } \\
\text { precision tinted ophthalmic } \\
\text { lenses: a case report }\end{array}$ & $\begin{array}{l}\text { Birmingham, England } \\
\qquad \mathrm{N}=1 \\
\text { Visual stress secondary } \\
\quad \text { to stroke }\end{array}$ & $\begin{array}{l}\text { Favorable. Case study of visual stress secondary to stroke, treated with the use } \\
\text { of overlays and spectral filters, whose initial chromaticity was changed after the } \\
\text { second stroke. There was an increase of } 40 \% \text { in reading rate with the use of } \\
\text { overlays, and of } 32 \% \text { after one month had passed. }\end{array}$ \\
\hline $\begin{array}{l}\text { Henderson, Tsogka, } \\
\text { and Snowling } \\
\quad(2013)\end{array}$ & $\begin{array}{l}\text { Questioning the benefits that } \\
\text { coloured overlays can have } \\
\text { for reading in students with } \\
\text { and without dyslexia }\end{array}$ & $\begin{array}{l}\text { York, England } \\
\qquad N=16+26 \\
\text { Visual stress and Dyslexia }\end{array}$ & $\begin{array}{l}\text { Partially Favorable. Both the grou } \\
\text { group read faster with the use of } 0 \\
\text { ( } 75 \%, 63 \% \text { and } 44 \%) \text {, when com } \\
\text { increased in at least } \geq 5 \%, \geq 8 \% \text { an } \\
\text { no improvement with overlays in c }\end{array}$ \\
\hline $\begin{array}{l}\text { Hollingsworth, } \\
\text { Ludlow, Wilkins, } \\
\text { Calver, and Allen } \\
\text { (2015) }\end{array}$ & $\begin{array}{l}\text { Visual performance and } \\
\text { the use of colored filters in } \\
\text { children who are deaf }\end{array}$ & $\begin{array}{l}\text { Cambridge, England } \\
\qquad \mathrm{N}=31+39 \\
\text { Visual stress and profound } \\
\text { deafness }\end{array}$ & $\begin{array}{l}\text { Favorable. All the deaf youths chose at least one overlay, of which Yellow was } \\
\text { the most frequent }(45 \%) \text {. In its turn, in the hearing control group, } 67 \% \text { chose at } \\
\text { least one overlay, though none opted for the Yellow. Deaf people that chose Yellow } \\
\text { increased in } 14 \% \text { their reading rate in the reading rate test and } 9 \% \text { in the deaf- } \\
\text { adapted version, with no statistical difference in the other deaf people and the } \\
\text { hearing control group. }\end{array}$ \\
\hline $\begin{array}{l}\text { Monger, Wilkins and } \\
\quad \text { Allen (2015) }\end{array}$ & $\begin{array}{l}\text { Identifying visual stress during } \\
\text { a routine eye examination }\end{array}$ & $\begin{array}{l}\text { Cambridge, England } \\
\qquad \mathrm{N}=73 \\
\text { Visual stress }\end{array}$ & $\begin{array}{l}\text { Favorable. } 36 \% \text { and } 14 \% \text { of the college students had a gain of at least } \geq 5 \% \text { and } \\
\geq 10 \% \text { in their reading rate when using overlays, respectively. }\end{array}$ \\
\hline $\begin{array}{l}\text { Ludlow and Wilkins } \\
\qquad(2016)\end{array}$ & $\begin{array}{l}\text { Atypical Sensory behaviours } \\
\text { in children with Tourette's } \\
\text { Syndrome and children with } \\
\text { Autism Spectrum Disorders }\end{array}$ & $\begin{array}{l}\text { Midlands and London, } \\
\text { England } \\
\mathrm{N}=12+12+12 \\
\text { Visual stress, Tourette } \\
\text { Syndrome, Autism } \\
\text { Spectrum Disorder }\end{array}$ & $\begin{array}{l}\text { Favorable. Gain greater than } \geq 15 \% \text { in reading rate with the use of overlays was } \\
\text { verified in Tourette syndrome }(50 \%) \text { and autism spectrum disorder }(33 \%) \text {, though } \\
\text { not in the control group }(0 \%) \text {. }\end{array}$ \\
\hline $\begin{array}{l}\text { Garcia, } \\
\text { Momensohn-Santos, } \\
\text { Vilhena (2017) }\end{array}$ & $\begin{array}{l}\text { Effects of Spectral Overlays } \\
\text { on Reading Performance of } \\
\text { Brazilian Elementary School } \\
\text { Children }\end{array}$ & $\begin{array}{l}\text { Jacareí, São Paulo, Brazil } \\
\qquad \mathrm{N}=68 \\
\text { Visual stress in typical } \\
\text { schoolchildren with no } \\
\text { problems of visual or } \\
\text { auditory acuity }\end{array}$ & $\begin{array}{l}\text { Favorable. } 31 \%, 22 \%, 18 \% \text { and } 13 \% \text { of } 5 \text { th- and } 6 \text { th-grade students of an elementary } \\
\text { school had gains greater than } \geq 5 \%, \geq 8 \%, \geq 10 \% \text { and } \geq 15 \% \text { in reading rate with } \\
\text { the use of overlays, respectively. Students with severe visual discomfort in reading } \\
\text { ( } n=11 \text { ) were three times more likely to improve their reading rate with an overlay } \\
\text { when compared with the less uncomfortable participants. }\end{array}$ \\
\hline $\begin{array}{l}\text { Garcia, Vilhena, } \\
\text { Guimarães, Pinheiro } \\
\text { and Momensohn- } \\
\text { Santos (2019) }\end{array}$ & $\begin{array}{l}\text { Relation between auditory and } \\
\text { visual temporal processing in } \\
\text { reading ability }\end{array}$ & $\begin{array}{l}\text { Jacareí, São Paulo, Brazil } \\
\qquad \mathrm{N}=26+42 \\
\text { Visual stress and auditory } \\
\text { temporal processing } \\
\quad \text { disorder }\end{array}$ & $\begin{array}{l}\text { Favorable. Participants with auditory temporal processing disorder }(n=26) \text { had } \\
\text { more visual stress symptoms, lower reading rate, and were three times more likely } \\
\text { to improve their reading rate with the use of spectral overlays when compared with } \\
\text { the control group }(n=42) \text {. }\end{array}$ \\
\hline $\begin{array}{l}\text { Guimarães, Vilhena, } \\
\text { Loew, Guimarães } \\
\text { (2019) }\end{array}$ & $\begin{array}{l}\text { Spectral overlays for reading } \\
\text { difficulties: Oculomotor } \\
\text { function and reading } \\
\text { efficiency among children and } \\
\text { adolescents with visual stress }\end{array}$ & $\begin{array}{l}\text { Belo Horizonte, Minas } \\
\text { Gerais, Brazil } \\
\quad \mathrm{N}=323 \\
\text { Visual stress }\end{array}$ & $\begin{array}{l}\text { Favorable. Eight- to seventeen-year-old participants with visual stress, when using } \\
\text { overlays and evaluated with an eye tracker, reduced the number of eye fixations and } \\
\text { regressions }(p<0.001) \text {, with an increase in perceptual reach, number of words } \\
\text { read per minute, relative efficiency, and text comprehension }(p<0.001) \text {. The effect } \\
\text { of the overlays is significantly higher in children when compared with adolescents } \\
(p<0.01) \text {. The most frequent overlays were the Purple, Gray and Turquoise. }\end{array}$ \\
\hline
\end{tabular}

Source: the author, 2019. 


\section{LITERATURE REVIEW}

A total of 12 scientific articles were reviewed, focusing on the results of the effect of spectral overlays on different visual parameters (oculomotor, ocular accommodation), facial recognition, and reading (reading rate, relative efficiency, and comprehension). The reviewed articles verified that the overlays have a more expressive effect when the visual stress is associated with conditions that present sensory alterations, and with cortical hyperactivity.

In two articles, Allen et al. ${ }^{16,17}$ verified the effect of the spectral overlays on the reading rate and amplitude of ocular accommodation. In the first study ${ }^{16}$, participants with visual stress $(n=11$; Mean age $=20.6$ years; from 18 to 25 years old), using spectral overlays, improved their reading rate in $9.9 \%$ (from 152 to 167 words per minute) and reduced the accommodation lag, while the two control groups did not present significant difference $(n=11)$. In the second study ${ }^{17}$, participants with visual stress $(n=18$; Mean age $=20.9 \pm 2.4$ years; from 18 to 25 years old), using spectral overlays, improved their reading rate in $10.4 \% \pm 4.8 \%$ and had a $45 \%$ reduction in accommodation lag (from $0.95 \mathrm{D}$ to 0.52 $\mathrm{D}, p=0.0001)$, while the control group $(n=18)$ did not present any significant difference. In both studies, the groups of participants with visual stress, when under the intervention of overlays, reduced ocular accommodations lag and leveled with the control groups' results.

The only study with unfavorable results for the use of overlays $^{18}$ reported that, with the use of overlays (ideal, not-ideal, transparent), no significant difference was found between the reading performance of children with reading difficulties due to visual stress $(n=47)$ and that of children from the control group $(n=14)$. Some factors lead the study to be questioned: 1) The Irlen method is a screening test and not a visual stress diagnostic one, so it is subject to possible specificity deviations; 2) Half of the children (54.3\%) presented uncorrected optical problems, which probably interfered with their reading abilities; 3 ) Most of the participants with visual stress $(72.1 \%, n / N=31 / 43)$ did not reach the lenient cutoff criterion of $\geq 5 \%$ in the rate of reading test with the use of overlays, therefore considered false positives; 4) The prolonged use of overlays for at least two weeks, and the clinical significance cutoff criterion of $\geq 15 \%$ in the rate of reading test $(7.0 \%, n / N=4 / 57)$ were not considered in the diagnosis classification of the participants with visual stress; 5) Gain higher than $\geq 5 \%$ in the RRT with the use of overlays, observed in one-third of the children with reading difficulties $(31 \%$, $n / N=19 / 61$ ), was not considered; 6) Use of an alternative version of the RRT with enlarged font size, which improves visual comfort and neutralizes the purpose of the RRT (i.e., to intensify visual stress); 7) The standard deviation higher than that of previous studies suggests high sample heterogeneity; and 8) The reduced size of the control group $(n=14)$ hindered statistical analyses with greater power than those used.

Participants with autism spectrum disorder $(n=15$; Mean age $=13 \pm 6.2$ years, from 8 to 17 years old) were compared with a control group $(n=15 ; 12.4 \pm 4.1$ years) regarding reading rate and recognition of facial expressions of emotion ${ }^{19}$. In the baseline, the number of words read per minute (reading rate) of the participants with autism spectrum disorder (mean $=86.5 \pm 33.7$ ) was lower than that of the control group (mean $=117.3$ $\pm 29.7)\left(t_{(28)}=2.02, p<0.05, d=1.00\right)$; however, the groups leveled when using overlays (Mean $=95.6 \pm$ 37.2 and $120.8 \pm 30.6)\left(t_{(28)}=0.54, p=0.06\right)$. More words were read with overlays (Mean $=108.2 \pm 35.9$ ) than without them (Mean $=101.9 \pm 34.9)\left(t_{(29)}=3.85, p\right.$ $<0.001, d=0.20$ ). More participants in the group with autism spectrum disorder (80\%), when using overlays, obtained a gain of at least $\geq 5 \%$ in the reading rate, when compared with the control group (33\%) $\left(X^{2}{ }_{(1)}=6.7, p<\right.$ $0.05)$. In the second assessment, when using overlays, the participants with autism spectrum disorder had an $18 \%$ improvement in recognition of facial expressions of emotion in a multiple-choice test with 28 images of the periocular region $\left(t_{(14)}=2.37, p<0.05\right)$, without any significant difference in the control group. The authors ${ }^{19}$ argued that these results are evidence that the abnormality in low-level visual perception can be responsible for part of the autistics' difficulties in processing and paying attention to the facial expressions.

In a second study from the same authors ${ }^{20}$ with clinical groups, a comparison was made between participants diagnosed with Tourette syndrome $(n=$ 12 , Mean age $=9.8 \pm 1.8$, from 6 to 12 years), autism spectrum disorder $(n=12$, Mean age $=9.8 \pm 2.3$, from 6 to 13 years), and a control group ( $n=12$, Mean age $=$ $20.7 \pm 2.2$, from 6 to 13 years). Tourette syndrome is a neurological disorder characterized by the combination of motor and vocal tics. A gain of more than $\geq 15 \%$ in reading rate, with the use of overlays, was verified in Tourette Syndrome (50\%) and autism spectrum disorder $(33 \%)$, but not in the control group $(0 \%)$. Both the patients with Tourette $\left(t_{(11)}=3.7, p<0.05\right)$ and autism $\left(t_{(11)}=2.6, p<0.05\right)$ reported more visual stress symptoms without the overlays, but there was no 
difference in the control group $\left(t_{(11)}=2.2, p=0.07\right)$. Both clinical conditions are associated with atypical sensory processing with visual cortex hyperexcitability.

A case study ${ }^{21}$ identified visual stress secondary to stroke, treated with overlays and spectral filters, whose initial chromaticity was changed after the second stroke. The initial complaints were photophobia, blurring in the left visual field, and severe headache on the right parietal side. There was a $40 \%$ increase in the reading rate with the use of overlay (from 119 to 167 words per minute) and, after a month passed, a 32\% increase (from 125 to 165 words per minute). The patient reported that overlay dramatically reduced the page brightness, making it comfortable to view.

All the deaf youths chose at least one overlay (whereas control, 67\%) ${ }^{22}$. The deaf people who chose Yellow (45\%) increased their reading rate by $14 \%$ in the rate of reading test and $9 \%$ in the deaf-adapted version, with no statistical difference in the other deaf people and the hearing control group. The authors ${ }^{22}$ reinforce that deaf children are twice disadvantaged in reading, as they present reduced visual and phonological skills. Since profound deaf people do not have phonological access when they read ${ }^{23}$, they are more dependent on the visual components of the characters' graphical patterns; moreover, reading difficulty can result in part from a perception or visual processing deficit.

Both the dyslexic college students' group ( $n=16$; from 19 to 30 years old) and the control group ( $n=$ 26) read faster when using the overlays ${ }^{24}$. Regardless of the group, individuals with lower reading rates are more likely to present higher reading rate gains with an overlay than those who already have higher reading rates. More participants of the dyslexic group $(75 \%$, $63 \%$ and $44 \%$ ), when compared to the control group $(48 \%, 46 \%, 35 \%)$, increased in $\geq 5 \%, \geq 8 \%$ and $\geq 10 \%$ their reading rate, respectively - i.e., more dyslexic people met the visual stress criterion of immediate reading improvement when using overlay.

In a study with an unselected sample of college students $(N=73$, Mean age $=20.2 \pm 2.4$ years, from 18 to 30 years, $26 \%$ men $)^{25}$, with the use of overlays, $36 \%$ of the participants obtained at least $\geq 5 \%$ gain in their reading rate, and $14 \%$ obtained more than $\geq 10 \%$ gain. There was no association between the increase in reading rate and the following routine ophthalmological parameters: refractive errors, visual acuity, stereopsis, accommodation amplitude, near point of convergence, color vision, and ocular motility. There was a significant difference, although not clinically relevant, in near associated heterophoria.

Two articles ${ }^{14,15}$ investigated visual stress in the same populational sample of students $(N=68$, Mean age $=11.2 \pm 0.7$ years, from 9 to 12 years, $53 \%$ boys), $5^{\text {th }}$ and $6^{\text {th }}$ graders from an elementary school of São Paulo, Brazil. In the first article ${ }^{14}$, it was demonstrated that $31 \%, 22 \%, 18 \%$ and $13 \%$ of the students had a gain of at least $\geq 5 \%, \geq 8 \%, \geq 10 \%$ and $\geq 15 \%$ in their reading rates, respectively, when using spectral overlays. In other words, at least one out of 10 students had a significant improvement in reading rate with the spectral overlays. Students with severe visual stress symptoms in reading were three times more likely to improve their reading rate with the overlay when compared to the control group (odds ratio $=3.36$ ). In the second article $^{15}$, the participants screened with auditory temporal processing disorder $(n=26)$ presented more visual stress symptoms, lower reading rate, and were three times more likely to improve their reading rate using the spectral overlays, when compared with the control group ( $n=42)$.

In the most recent article ${ }^{26}, 323$ eight- to seventeenyear-old youths with visual stress were evaluated with an eye tracker. The great number of eye fixations and regressions observed in this participants' baseline, in comparison with the norms, can be an indicator of corrective eye movements to verify the words (or graphemes) that were not sufficiently attended, as well as of vergence adjustment, and inefficient line tracking. The participants with visual stress, when reading with spectral overlays, presented immediate and significant gains in ocular motor skills (fewer fixations and regressions) and reading efficiency (increase in perceptual span, reading rate, relative efficiency, and text comprehension), when compared with the baseline $(p<0.001)$. Regarding the reading rate, children and adolescents with spectral intervention read on average $28 \%$ and $20 \%$ more words per minute, respectively. The immediate reduction in the number of fixations and regressions with the overlays presented a significant age effect $(p<0.01)$, possibly due to the children starting at a worse baseline.

\section{CONCLUSION}

This present integrative review described the use of spectral overlays in 12 articles, in order to investigate the impact of this intervention on people with visual stress or this condition associated with other conditions. The articles' results were consistently favorable to 
the use of overlays, with improvement in visual parameters (ocular accommodation, eye movement, visual comfort), facial recognition, and reading (reading rate, relative efficiency, and comprehension). The associated conditions investigated were autism spectrum disorder, Tourette syndrome, stroke, deafness, dyslexia, and auditory temporal processing disorder. The overlays' effect is more expressive when the visual stress is associated with cortical hyperactivity and conditions that present sensory alterations. This review corroborates the conclusions drawn by Evans and Allen in their systematic review of 10 controlled studies. Future investigations, besides evaluating reading rates, should consider the long-term therapeutic effects of the overlays in the classroom, since the purpose of this intervention is to eliminate barriers in visual acquisition and processing, during the learning process and reading proficiency consolidation.

\section{REFERENCES}

1. Guimarães MR, Vilhena $D A$, Guimarães $R Q$. Relation between optical, neurovisual and cognitive processing in reading difficulties. Revista Acta Científica. 2017;8(1):193-212. doi:10.21745/ ac08-18

2. Irlen HL. Scotopic sensitivity? Irlen syndrome: hypothesis and explanation of the syndrome. $\mathrm{J}$ Behav Optom. 1994;5(62):65-6.

3. Loew SJ, Watson K. A prospective genetic marker of the visual-perception disorder Meares-Irlen syndrome. Percept Mot Skills. 2012;114(3):870-82. doi:10.2466/24.10.11.27.PMS.114.3.870-882

4. Stein J, Walsh V. To see but not to read; the magnocellular theory of dyslexia. Trends Neurosci. 1997;20(4):147-52. doi:10.1016/ s0166-2236(96)01005-3

5. Kriss I, Evans BJ. The relationship between dyslexia and Meares-Irlen Syndrome. J Res Read. 2005;28(3):350-64. doi:10.1111/j.1467-9817.2005.00274.x

6. Scott L, McWhinnie H, Taylor L, Stevenson $\mathrm{N}$, Irons $\mathrm{P}$, Lewis $\mathrm{E}$ et al. Coloured overlays in schools: orthoptic and optometric findings. Ophthalmic Physiol Opt. 2002;22(2):156-65. doi:10.1046/j.1475-1313.2002.00009.x

7. Evans BJ, Allen PM. A systematic review of controlled trials on visual stress using Intuitive Overlays or the Intuitive Colorimeter. J Optom. 2016;9(4):205-18. doi:10.1016/j.optom.2016.04.002
8. Guimarães MR, Guimarães RQ. Avaliação da visão funcional em distúrbios de aprendizagem - O papel do oftalmologista nos déficits de visão e aprendizagem. In: Ventura LO, Travassos SB, Silva OA, Dolan M (eds). Dislexia e distúrbios de aprendizagem. Rio de Janeiro: Cultura Médica; 2012. p. $159-74$.

9. Vidyasagar TR, Pammer K. Dyslexia: a deficit in visuo-spatial attention, not in phonological processing. Trends Cogn Sci. 2010;14(2):57-63. doi:10.1016/j.tics.2009.12.003

10. Evans BJ, Allen PM, Wilkins AJ. A Delphi study to develop practical diagnostic guidelines for visual stress (pattern-related visual stress). J Optom. 2017;10(3):161-8. doi:10.1016/j.optom.2016.08.002

11. Wilkins AJ, Jeanes RJ, Pumfrey PD, Laskier M. Rate of reading test: its reliability, and its validity in the assessment of the effects of coloured overlays. Ophthalmic Physiol Opt. 1996;16(6):491-7. doi:10.1046/j.1475-1313.1996.96000282.x

12. Vilhena $D A$, Guimarães $M R$, Guimarães $R Q$, Pinheiro AMV. Adaptation of the Reading Rate Test: selection of words. Award for best work in the Young Senior Researcher category. Proceedings of the Encontro Mineiro de Neuropsicologia Escolar. Belo Horizonte: UFMG; 2019.

13. Vilhena $D A$, Guimarães $M R$, Guimarães $R Q$. Improvement in reading performance using spectral overlays: systematic review and meta-analyses. Psicol argum. 2018;36(93):343-61. doi:10.7213/ psicolargum.36.93.AO05

14. Garcia ACO, Momensohn-Santos TM, Vilhena DA. Effects of spectral overlays on reading performance of Brazilian elementary school children. Folia Phoniatr Logop. 2017;69(5-6):219-25. doi:10.1159/000484139

15. Garcia ACO, Vilhena DA, Guimarães MR, Pinheiro ÂMV, Momensohn-Santos TM. Association between auditory temporal and visual processing in reading skill. Rev. CEFAC. 2019;21(5):1-10. doi:10.1590/1982-0216/20192156119

16. Allen PM, Hussain A, Usherwood C, Wilkins AJ. Pattern-related visual stress, chromaticity, and accommodation. Invest Ophthalmol Vis Sci. 2010;51(12):6843-9. doi:10.1167/iovs.09-5086

17. Allen PM, Dedi S, Kumar D, Patel T, Aloo M, Wilkins AJ. Accommodation, pattern glare, and coloured overlays. Perception. 2012;41(12):1458-67. doi:10.1068/p7390 
18. Ritchie SJ, Della Sala S, McIntosh RD. Irlen colored overlays do not alleviate reading difficulties. Pediatrics. 2011;128(4):e932-8. doi: 10.1542/ peds.2011-0314

19. Ludlow AK, Taylor-Whiffen E, Wilkins AJ. Coloured filters enhance the visual perception of social cues in children with autism spectrum disorders. ISRN Neurol. 2012:298098. doi:10.5402/2012/298098

20. Ludlow AK, Wilkins AJ. Atypical sensory behaviours in children with Tourette's Syndrome and in children with Autism Spectrum Disorders. Res Dev Disabil. 2016;56(1):108-16. doi:10.1016/j.ridd.2016.05.019

21. Beasley IG, Davies LN. Visual stress symptoms secondary to stroke alleviated with spectral filters and precision tinted ophthalmic lenses: a case report. Clin Exp Optom. 2013;96(1):117-20. doi:10.1111/j.1444-0938.2012.00794.x

22. Hollingsworth RS, Ludlow AK, Wilkins AJ, Calver RI, Allen PM. Visual performance and the use of colored filters in children who are deaf. Optom Vis Sci. 2015;92(6):690-9. doi:10.1097/ OPX.0000000000000595

23. Pinheiro AMV, Rocha-Toffolo AC, Vilhena DA. Reading strategies for the profoundly deaf Libras users: benefits of speech and lip reading for strengthening linguistic skills. Estud. psicol. 2020;37(1):1-12. doi:10.1590/1982-0275202037e190003.

24. Henderson LM, Tsogka N, Snowling MJ. Questioning the benefits that coloured overlays can have for reading in students with and without dyslexia. J Res Spec Educ Needs. 2013;13(1):57-65. doi:10.1111/j.1471-3802.2012.01237.x

25. Monger L, Wilkins AJ, Allen PM. Identifying visual stress during a routine eye examination. J Optom. 2015;8(2):140-5. doi:10.1016/j.optom.2014.10.001

26. Guimarães MR, Vilhena DA, Loew SJ, Guimarães $R Q$. Spectral overlays for reading difficulties: oculomotor function and reading efficiency among children and adolescents with visual stress. Percept Mot Skills. 2020;127(2):490-509. doi: $10.1177 / 0031512519889772$ 